\begin{tabular}{|c|c|c|}
\hline $\begin{array}{l}\text { PKS } \\
\text { PUBLIC } \\
\text { KNOLEDGE } \\
\text { ROOLIEC }\end{array}$ & $\begin{array}{c}\text { Revista de GEOGRAFIA } \\
\text { (RECIFE) } \\
\text { http://www.revistautpe.tor/revistageografitia }\end{array}$ & $\begin{array}{l}\text { OJS } \\
\frac{\text { OPEN }}{\text { OPENAL }} \text { JYUNAL } \\
\text { GYSTMS }\end{array}$ \\
\hline
\end{tabular}

\title{
EVIDÊNCIAS MORFOLÓGICAS DE CONDIÇÕES PALEOCLIMÁTICAS ÚMIDAS NO SEMIÁRIDO BRASILEIRO
}

\author{
Frederico de Holanda Bastos ${ }^{1}$ \\ ${ }^{1}$ Universidade Estadual do Ceará - UECE. E-mail: fred.holanda@uece.br
}

Artigo recebido em 01/07/2018 e aceito em 02/08/2018

\begin{abstract}
RESUMO
O semiárido brasileiro constitui uma região de grande complexidade paisagística no cenário continental cuja interpretação de seu relevo tem evoluído de maneira significativa ao longo das últimas décadas. Entre as décadas de 1950 e 1970 constata-se um período de interpretações clássicas baseadas em adaptações da Teoria da Pediplanação de Lester King. Com a evolução das pesquisas morfoestruturais e morfopedológicas a partir da década de 1990, diversas interpretações novas surgiram, amparadas também em métodos de geocronologia, que contribuíram significativamente na interpretação da gênese, evolução e distribuição espacial dos compartimentos geomorfológicos regionais. Mesmo com o rico acervo histórico de interpretações do relevo do semiárido nordestino, alguns modelos interpretativos, associados a condições paleoclimáticas úmidas, encaixam-se perfeitamente na interpretação da geomorfogênese regional, de onde pode-se destacar os modelos de Etchplanação (WAYLAND, 1933 e BÜDEL, 1957) e o de Aplainamento por Mudanças Climáticas (MILLOT, 1983). Algumas unidades morfológicas do semiárido nordestino apresentam claras evidências de condições paleoclimáticas úmidas com destaque para relevos graníticos, paleossolos lateríticos e algumas feições cársticas, o que permite uma tentativa de adaptação dos modelos evolutivos anteriormente mencionados.
\end{abstract}

Palavras-chaves: Etchplanação, Relevos Saprolíticos, Nordeste Brasileiro, Duplo Aplainamento.

\section{MORPHOLOGICS EVIDENCES OF HUMID PALEOCLIMATIC CONDITIONS IN THE BRAZILIAN SEMI-ARID}

\begin{abstract}
The Brazilian semi-arid is a region of great landscape complexity in the continental context whose interpretation of its relief has evolved greatly over the last decades. Between the 1950s and 1970s there was a period of classical interpretations based on adaptations of Lester King's Pediplanation Theory. With the evolution of morpho-structural and morpho-pedagogical research since the 1990s, several new interpretations have emerged, also supported by geochronology methods, which have contributed significantly to the interpretation of the genesis, evolution and spatial distribution of regional geomorphological compartments. Even with interpretations of the Northeastern semi-arid relief presented, some interpretative models, associated with humid paleoclimatic conditions, fit perfectly in the interpretation of regional geomorphogenesis, with emphasis on the theories of Etchplanation (WAYLAND, 1933 and BÜDEL, 1957) and the Planning for Climate Change (MILLOT, 1983). Some morphological units of the Brazilian semi-arid region present clear evidences of humid paleoclimatic conditions, highlighting granitic landforms, lateritic paleosols and some karstic features, which allows an adaptation of the previously mentioned evolutionary models.
\end{abstract}

Keywords: Etchplanation, Saprolithic Reliefs, Semi-arid of Northeast of Brazil, Two Stage Planing. 


\section{INTRODUÇÃO}

O semiárido brasileiro (Figura 01) abrange a parte central da região Nordeste e uma pequena parcela setentrional da região Sudeste, o que representa cerca de $11 \%$ do território nacional, constituindo uma área de grande diversidade paisagística em decorrência da complexidade de fatores naturais associados à geologia, relevo, clima e solos. Em termos ecológicos predomina o recobrimento das caatingas nas superfícies sertanejas, sendo muito comum a ocorrência de enclaves de representantes de outros biomas brasileiros como a mata atlântica e o cerrado, dependendo das condições edafoclimáticas de cada setor.

Figura 1: Delimitação oficial do semiárido brasileiro

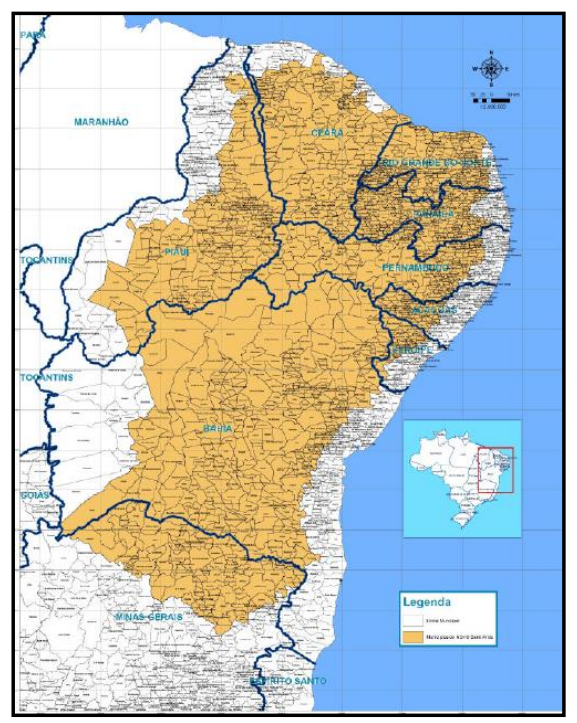

Fonte: Ministério da Integração Nacional (2005)

Trata-se de uma condição climática semiárida azonal tendo em vista as baixas latitudes em que se encontra, com predomínio de elevadas temperaturas médias, que giram em torno de $27^{\circ} \mathrm{C}$ a $29^{\circ} \mathrm{C}$ (AB'SÁBER, 1974) e um complexo sistema de circulação atmosférica com estações chuvosas que se concentram em um curto período do ano, cujos totais anuais podem chegar a $600 \mathrm{~mm}$ com balanço hídrico predominantemente negativo no decorrer do ano.

Apesar da complexidade paisagística anteriormente apresentada, pode-se afirmar que existe um predomínio de vastas superfícies de erosão (depressões sertanejas) pontilhadas de relevos residuais de dimensões variadas (maciços e inselbergs) cuja morfogênese regional tem sido muito debatida ao longo das últimas décadas.

As tentativas de interpretar o relevo nordestino apresentam diversos momentos marcantes pautados por diferentes pontos de vista metodológico de onde pode-se recortar dois 
momentos históricos importantes que são as interpretações clássicas das décadas de 1950/60/70, fundamentadas nos trabalhos de King (1956), e os trabalhos mais recentes apoiados em interpretações morfoestruturais e morfopedológicas, a partir da década de 1990.

Mesmo com as diversas abordagens apresentadas, existem teorias clássicas que podem perfeitamente ser aplicadas na interpretação do relevo do semiárido brasileiro tendo em vista as fortes evidências morfológicas de condições paleoclimáticas mais úmidas, que permitem a tentativa de adaptações de teorias como a da Etchplanação (WAYLAND, 1933; BÜDEL, 1957) e a de Aplainamento por Mudanças Climáticas (MILLOT, 1983).

Face ao exposto, o presente trabalho visa apresentar evidências morfológicas de condições paleoclimáticas mais úmidas em determinados recortes morfoestruturais de paisagens do Estado do Ceará e adjacências, com ênfase para paisagens graníticas, recobrimentos lateríticos e relevos cársticos.

\section{MATERIAIS E MÉTODOS}

A presente abordagem foi realizada a partir de pesquisas elaboradas no âmbito do Laboratório de Estudos Morfoestruturais e Pedológicos (LEMEP), vinculado ao Programa de Pós-Graduação em Geografia da Universidade Estadual do Ceará (UECE). Tais trabalhos envolvem diferentes recortes espaciais do Estado do Ceará com ênfase voltada para alguns relevos graníticos (Maciços de Meruoca, Uruburetama e Inselbergs de Quixadá), setores com recobrimento lateríticos (Maciço do Quincuncá e Glint da Ibiapaba) e algumas morfologias cársticas (Gruta de Ubajara e setores dos Maciços de Baturité, Machado e Quincuncá) (Figura 02).

A presente pesquisa foi elaborada a partir de levantamentos bibliográficos acerca dos aspectos geomorfológicos regionais do Nordeste brasileiro e de suas interpretações evolutivas, bem como dos recortes espaciais escolhidos, de forma mais detalhada. Em seguida foram feitos levantamentos cartográficos, interpretações e sobreposições de mapas temáticos, com ênfase para os mapas hipsométricos e geológicos, além da elaboração de cartografia própria da cada área. Finalizando, foram realizados diversos trabalhos de campo com intuito de interpretar os aspectos morfoestruturais em escala local de maneira a subsidiar a interpretação regional. 
Revista de Geografia (Recife) V. 35, No. 4 (especial XII SINAGEO), 2018

Figura 2: Recortes espaciais da presente pesquisa no contexto do Estado do Ceará

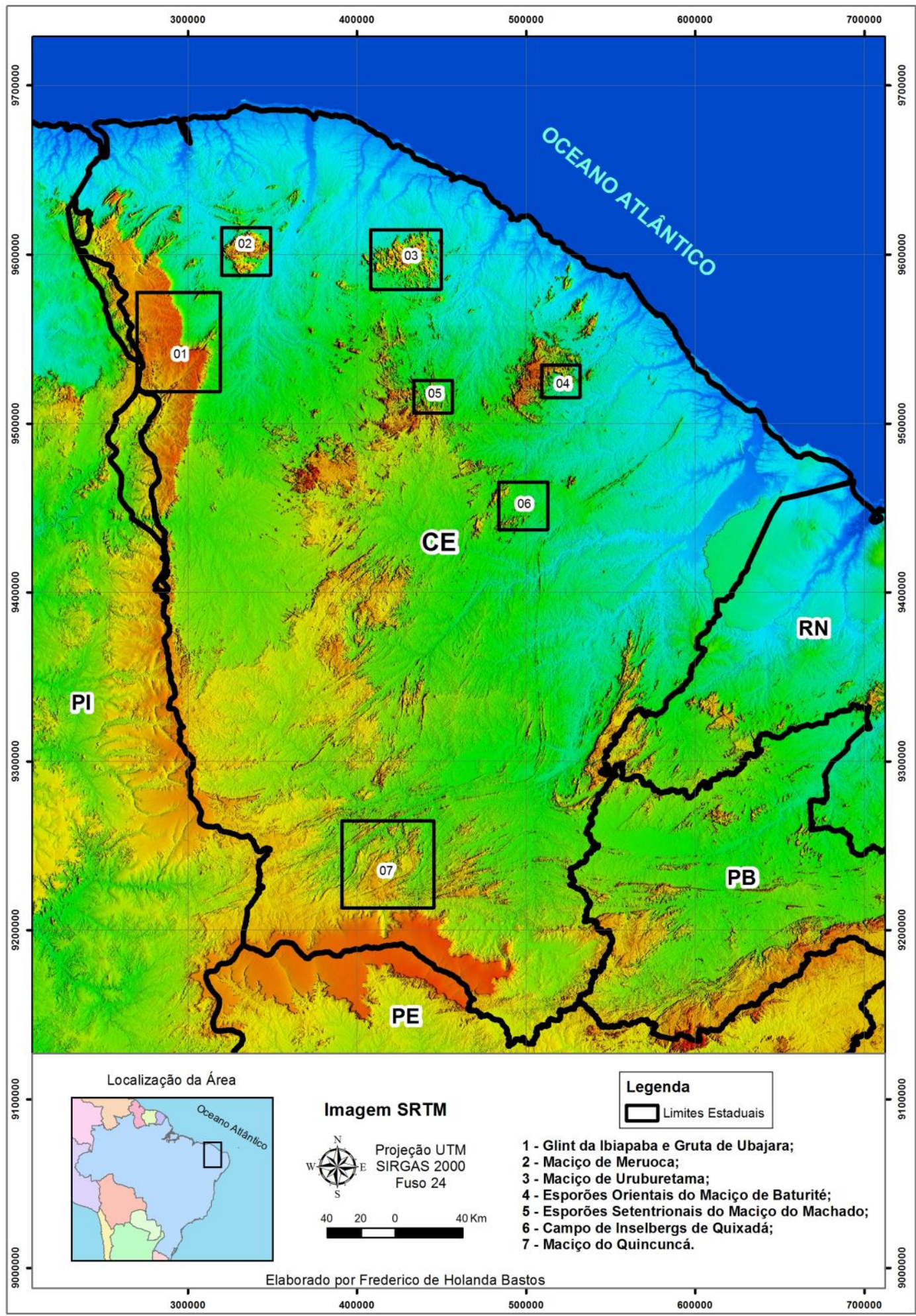

Fonte: Elaborado pelo autor 


\section{RELEVO NORDESTINO}

De maneira a subsidiar a apresentação da presente proposta de interpretação do relevo nordestino, é importante destacar, de forma sucinta, dois momentos marcantes na interpretação dos relevos nordestinos, aqui considerados como "Interpretações Clássicas" e "Interpretações Morfoestruturais e Morfopedológicas".

\section{Interpretações Clássicas (Décadas de 1950/60/70)}

As interpretações clássicas aqui consideradas constituem as teorias inspiradas no modelo de Pediplanação de King (1956) que são teorias que destacam a existência de superfícies de erosão escalonadas elaboradas a partir de soerguimentos regionais e flutuações climáticas alternadas de períodos secos e úmidos ao longo do Cenozoico. As diferentes superfícies erosivas também são propostas a partir de correlações altimétricas e geométricas associadas à interpretação de depósitos correlativos do Grupo Barreiras. Essas interpretações identificaram entre 3 e 5 superfícies de aplainamento no contexto regional de acordo com a interpretação de cada autor (AB'SABER, 1956; DRESCH, 1957; DEMANGEOT, 1960; ANDRADE E CALDAS LINS, 1965, BIGARELLA E ANDRADE, 1964; ANDRADE, 1968 E MABESOONE E CASTRO, 1975).

A aplicação dessas interpretações no contexto atual apresenta diversas fragilidades tendo em vista, dentre vários fatores, questões de escala, a complexidade morfoestrutural da região Nordeste e os avanços associados aos estudos geológicos, com ênfase à tectônica de placas. Cabe aqui destacar que a presente abordagem não visa analisar o mérito das interpretações morfogenéticas apresentadas, porém, é inquestionável a importância histórica desses trabalhos na evolução da ciência geomorfológica brasileira e nordestina.

\section{Interpretações Morfoestruturais e Morfopedológicas (A partir da década de 1990)}

A partir dos avanços nas áreas de geotecnologias e também de métodos relacionados às pesquisas geológicas, como no caso da utilização da geocronologia a partir de métodos de datação absoluta de amostras, pôde-se dispor de meios capazes de viabilizar interpretações geomorfológicas relacionando diretamente as variações morfológicas com a estrutura geológica e sua história (Análise Morfoestrutural), com ênfase muito importante ao papel da Tectônica (ou Neotectônica) além da erosão diferencial na configuração dos compartimentos geomorfológicos (PEULVAST e CLAUDINO SALES, 2003; PEULVAST e CLAUDINO SALES, 2004; CORREA et al., 2010; GURGEL et al., 2013; MAIA e BEZERRA, 2014; 
SAADI e TORQUATO, 1994; PEULVAST e BÉTARD, 2015). Nessa perspectiva cabe também destacar as interpretações das propriedades geomorfológicas das rochas e seus reflexos em diferentes escalas de análise.

Dentro dessa fase da pesquisa geomorfológica regional cabe também ressaltar a relação de rede de drenagem e seu controle estrutural (Geomorfologia Fluvial), tanto em macro como em micro escala. Nessa perspectiva diversos estudos relacionando as relações dos direcionamentos preferenciais das zonas de cisalhamento com a organização da rede de drenagem foram realizados.

Além das abordagens anteriormente apresentadas, merece destaque também algumas abordagens morfopedológicas contribuindo significativamente com a interpretação paleoclimática regional, além das condições climáticas atuais, e sua relação com a gênese dos diferentes tipos de alterações superficiais regionais em distintos compartimentos morfológicos (BÉTARD e PEULVAST, 2010; CORDEIRO et al., 2018).

\section{NOVAS PERSPECTIVAS DE INTERPRETAÇÃO DO RELEVO NORDESTINO}

Mesmo com as diversas interpretações geomorfológicas do semiárido nordestino, existem importantes evidências paleoclimáticas úmidas nos relevos que merecem adequações interpretativas. $\mathrm{Na}$ presente abordagem merecem destaque as teorias da "Etchplanação" (WAYLAND, 1933 e BÜDEL, 1957) e a do "aplainamento por mudanças climáticas" (MILLOT, 1983).

O modelo da Etchplanação advoga que para a evolução do relevo é necessária uma relativa quietude tectônica e a existência de condições climáticas tropicais semiúmidas responsáveis pelo desenvolvimento das superfícies de aplainamento (SALGADO, 2007). Nessa perspectiva, os processos geoquímicos e pedológicos possuem grande relevância na morfogênese das paisagens (VITTE, 2001).

A palavra etching é usada em Geomorfologia para descrever o processo de decomposição progressiva de uma rocha no interior de perfis de intemperismo profundo, cujas propriedades das rochas justificam as variações da espessura do regolito (MIGÓN, 2006). A remoção do manto de intemperismo expõe a base rochosa, cuja topografia é resultado direto da ação do intemperismo químico, caracterizando-se como uma etch surface (BÜDEL, 1982; MIGÓN, 2006).

A Teoria do Aplainamento por Mudanças Climáticas de Millot (1983) considera que as superfícies aplainadas podem ser explicadas com base nos processos ocorridos em regiões 
áridas ou semiáridas, que anteriormente estiveram submetidas a condições climáticas mais úmidas por tempo suficiente para que ocorresse um processo intenso de alteração do manto de intemperismo (SALGADO, 2007).

Na teoria de Millot (1977, 1983), os processos denudacionais em condições climáticas iniciais úmidas e semiúmidas não seriam suficientes para aplainar o relevo. Contudo, a intemperização do material por processos geoquímicos, em condições climáticas anteriormente úmidas ou semiúmidas, caracteriza-se como um estágio necessário e preparatório para a ação dos processos mecânicos superficiais, em climas áridos ou semiáridos, sendo estes que possuem alta capacidade de gerar aplainamentos (SALGADO, 2007), tento em vista que os processos erosivos são mais intensos em materiais já alterados e em condições climáticas mais secas, proporcionando, assim, o aplainamento do relevo (LIMA, 2018).

Cabe destacar que já existem abordagens interpretativas que consideram as teorias citadas de onde se pode destacar os trabalhos de Santos e Salgado (2010), Pelvast e Bétard (2015) e Cordeiro et al. (2018). Além dos trabalhos apresentados, algumas publicações já evidenciam condições paleoclimáticas mais úmidas tais como os trabalhos de Wang et al., (2004), Behling et al. (2000) e Lima (2008).

A presente abordagem consiste numa tentativa de adaptação de caráter teorético dos modelos relacionados com exposição de frentes de intemperismo associados a condições climáticas mais úmidas para alguns recortes espaciais do Estado do Ceará e adjacências relacionados com: 1. Exumação de feições saprolíticas em relevos graníticos; 2. Exumação de frentes de intemperismo sob recobrimentos lateríticos; e 3. Relevos cársticos.

\section{Relevos graníticos}

Os granitoides da Província Borborema, onde se localiza a presente área de estudo, estão predominantemente associados à Orogênese Brasiliana (ARTHAUD, 2007) que foi responsável por preenchimentos plutônicos preferencialmente dispostos no sentido NE-SW e E-W associados aos direcionamentos preferenciais das zonas de cisalhamento e lineamentos estruturais regionais (MAIA e BEZERRA, 2014; LIMA, 2018; MAIA et al. 2018). A atual exposição dessas estruturas, que se formaram em significativas profundidades na crosta, está associada a processos denudacionais relacionados a soerguimentos tectônicos e isostásicos e a ação da erosão diferencial. 
As paisagens graníticas do semiárido brasileiro apresentam feições que evidenciam condições paleoclimáticas mais úmidas, como no caso da exumação de algumas macroformas como inselbergs e bornhardts, além de feições saprolíticas como boulders, nubbins, tors $e$ castle koppies (MIGÓN, 2006; TWIDALE; VIDAL ROMANÍ, 2005).

No semiárido nordestino é comum encontrar formas de relevo saprolítico associadas a afloramentos do embasamento ígneo. Nessa perspectiva, formas relictuais derivadas de um paleomanto de alteração ( $g r u s$ ) associado a condições climáticas mais úmidas, evidenciam fases erosivas desencadeadas em períodos mais secos atuais, que removeram parcialmente os detritos friáveis resultantes da meteorização inicial mantendo apenas os antigos corestones que, após exumados, passam a receber a denominação de boulders (Figura 3). A configuração morfológica e/ou geométrica desses boulders justifica a ocorrência de feições como nubbins, tors e castle koppies (Figura 4).

Figura 3: Feições saprolíticas (boulders) em Lajedo de Pai Mateus, Cabaceiras, Paraíba

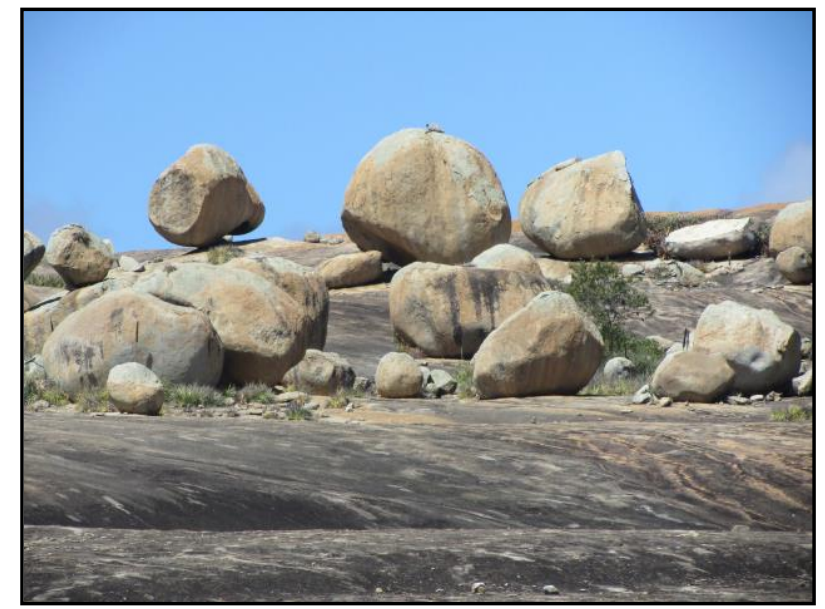

Foto: Rubson Pinheiro Maia, 2017

Figura 4: Castle koppie situado na vertente ocidental do maciço de Uruburetama, Irauçuba, Ceará

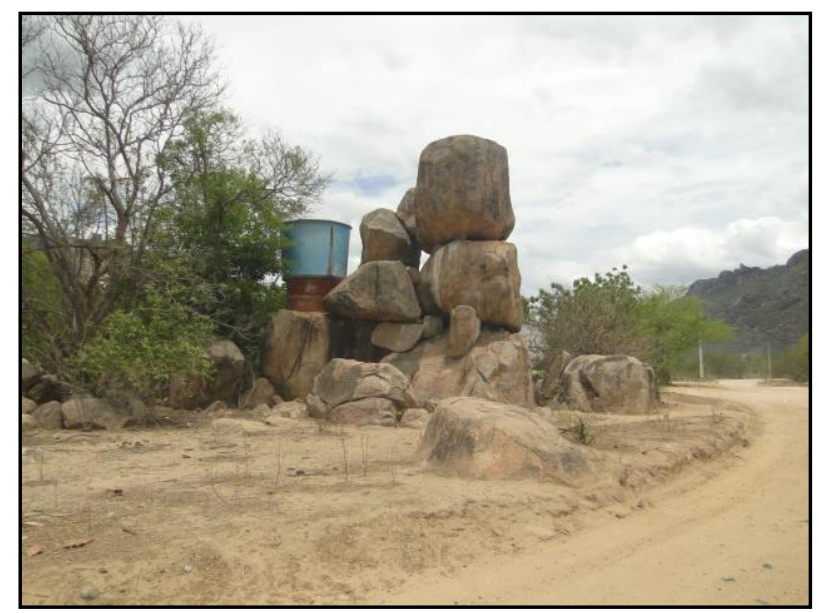

Foto: Frederico de Holanda Bastos, 2017 
Para Twidale (2002) a concepção de duplo aplainamento é a mais aceita para explicar a exumação e o desenvolvimento dos inselbergs, pois cada vez mais, tem se reconhecido que os componentes que regem a evolução associada aos campos de inselbergs estão relacionados a processos que ocorrem na base do regolito e não apenas em superfície, constituindo relevos remanescentes de erosão capazes de fornecer informações importantes sobre a evolução geomorfológica regional (LIMA, 2018). No Nordeste brasileiro é bastante comum a ocorrência de inselbergs dômicos também designados como bornhardts (Figuras 05 e 06).

Figura 5: Formas graníticas convexas (inselbergs dômicos) entre os municípios de Quixadá e Quixeramobim, Ceará

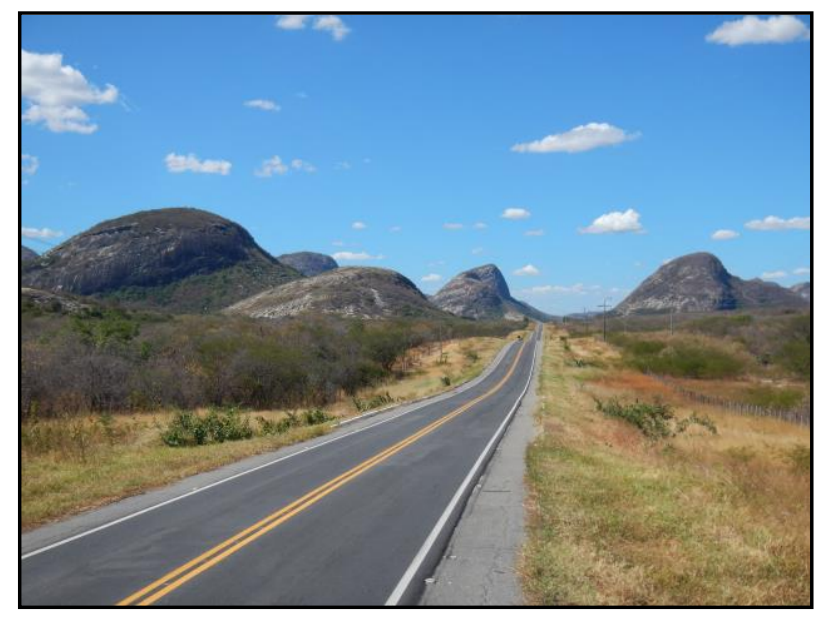

Foto: Rubson Pinheiro Maia, 2016

Figura 6: Bornhardt localizado no município de Quixadá, Ceará

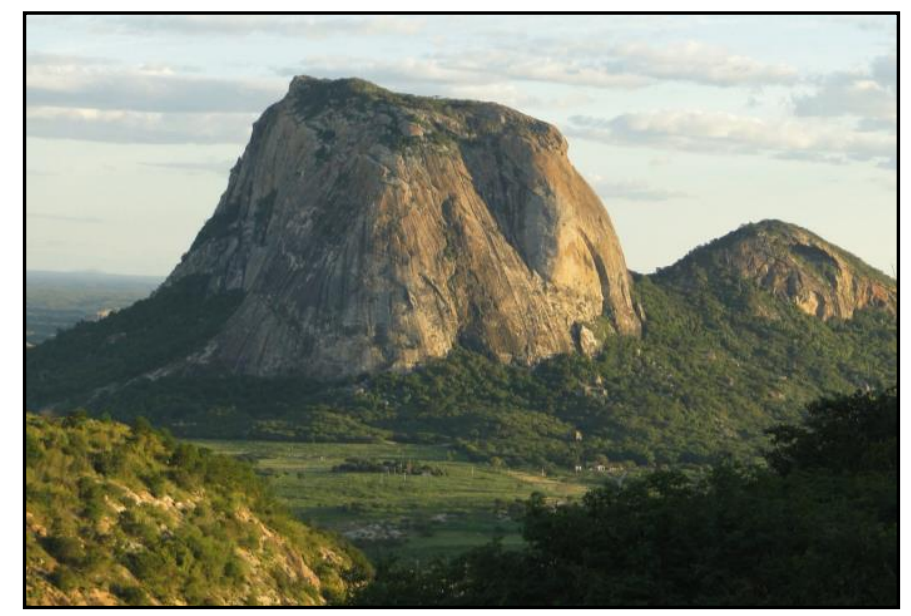

Foto: Frederico de Holanda Bastos, 2012 
Nas paisagens graníticas do Nordeste brasileiro também são muito comuns as microformas de meteorização (dissolução) tendo como exemplos os tafoni (Figura 07), alvéolos, caneluras ou karrens, gnammas e flared slopes (MAIA et al., 2018). A explicação da gênese de tais formas ainda apresenta enormes desafios à ciência geomorfológica, no entanto, pode-se afirmar que algumas dessas formas tiveram estágios evolutivos sob condições epigênicas, onde a concentração de $\mathrm{CO}_{2}$ é mais significativa permitindo maior atividade química. Corroborando com o modelo da etchplanação, destaca-se o flared slope (Figura 08) que constitui uma forma de relevo que pode estar associada a paleoníveis de dissolução epigênica, que contribui para indicar uma evolução por downwearing.

Figura 7: Tafone em inselberg nos setores ocidentais do maciço de Uruburetama, Irauçuba, Ceará

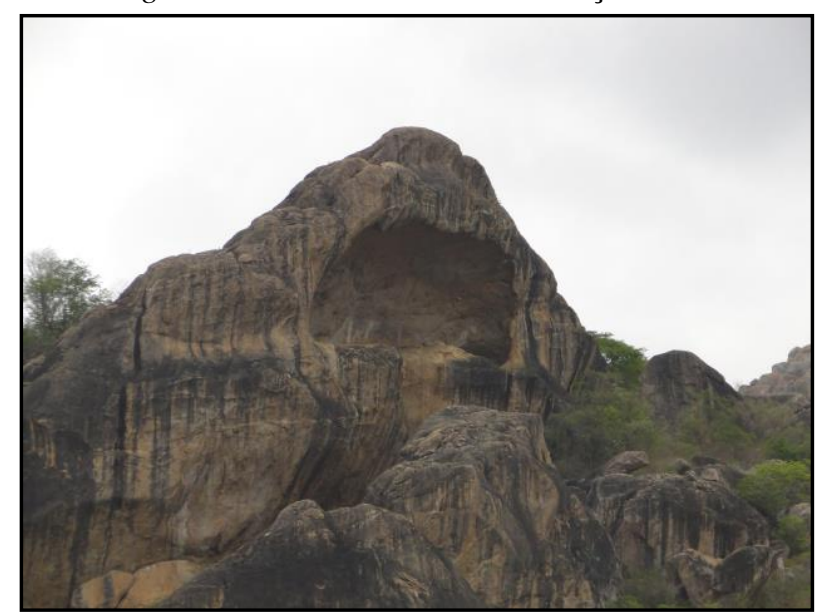

Foto: Frederico de Holanda Bastos, 2017

Figura 8: Flared slope em um inselberg de Quixadá, Ceará

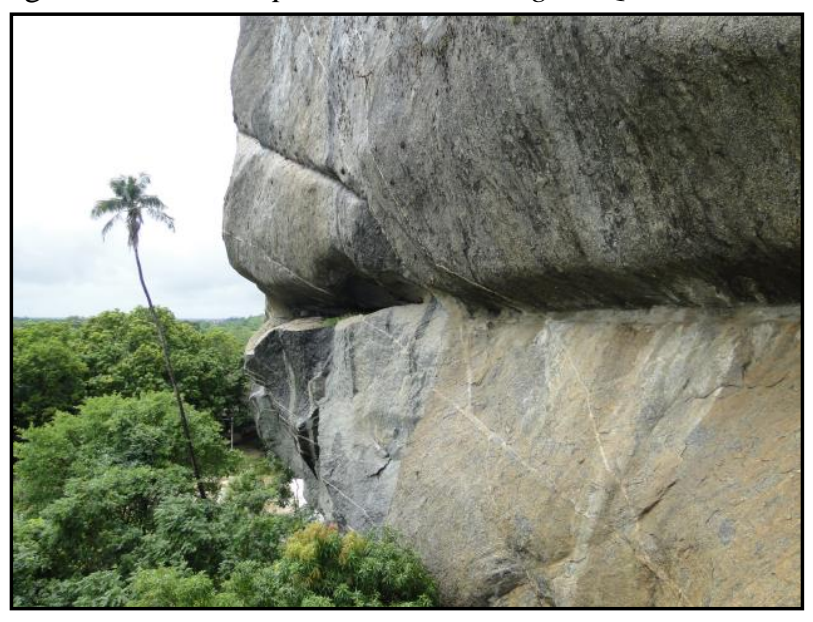

Foto: Frederico de Holanda Bastos, 2017 


\section{Recobrimentos Lateríticos}

As formações lateríticas constituem indicadores confiáveis da atuação de paleoclimas úmidos com condições de temperatura e umidade elevada (NAHON, 1991; TARDY, 1993; VASCONCELOS et al., 1994). Nos setores setentrionais da Província Borborema os recobrimentos lateríticos são encontrados de forma fragmentada constituindo superfícies tabulares como se pode observar em alguns trechos pré-litorâneos do Grupo Barreiras e alguns recobrimentos somitais de maciços cristalinos (Serras de Martins, Portalegre e Santana, no Rio Grande do Norte; e Serra do Quincuncá e adjacências, no Ceará (CORDEIRO et al., 2018).

Baseando-se nos dados de Lima (2008), considera-se o ápice de desenvolvimento de lateritas no Nordeste setentrional o Paleógeno. No caso específico do maciço do Quincuncá, constata-se que se trata de uma laterita autóctone (Figura 09) derivada da intemperização dos granitoides da Suíte Serra do Deserto (CORDEIRO, 2017). Tal intemperização ocorreu no pós-cretáceo associada à exumação desse setor do embasamento que estava recoberto pelos arenitos da Formação Exu, atualmente situada ao sul do Maciço do Quincuncá, cujo recuo se deu por erosão regressiva associada à inversão topográfica responsável pela morfogênese da chapada do Araripe (PEULVAST e BÉTARD, 2015).

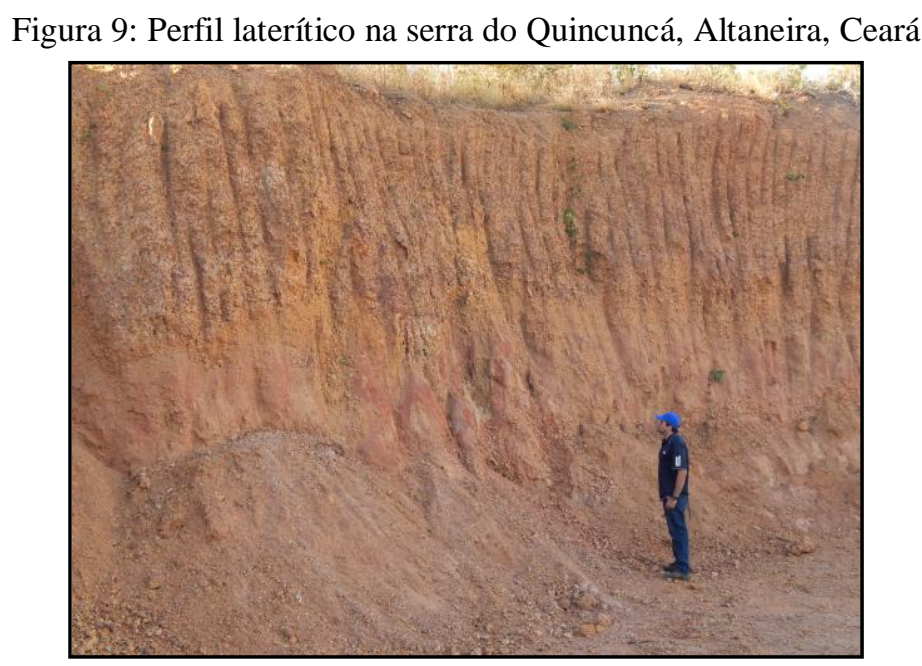

Foto: Frederico de Holanda Bastos, 2015

No maciço do Quincuncá constata-se que o recobrimento laterítico sustenta uma superfície tabular situada no topo de um relevo granítico aproximadamente na cota $700 \mathrm{~m}$ (Figura 10). Existem fortes evidências de que esses recobrimentos se estenderam para áreas bem mais amplas do embasamento no Terciário, restando atualmente apenas fragmentos. A remoção das crostas lateríticas pela ação erosiva atual expõe as frentes de intemperismo (etch 
suface) (Figura 11) contribuindo para a interpretação morfogenética a partir do modelo de Etchplanação.

Figura 10: Superfície tabular (no topo do relevo $-700 \mathrm{~m}$ ) sustentada pelas crostas lateríticas da serra do Quincuncá, Altaneira, Ceará

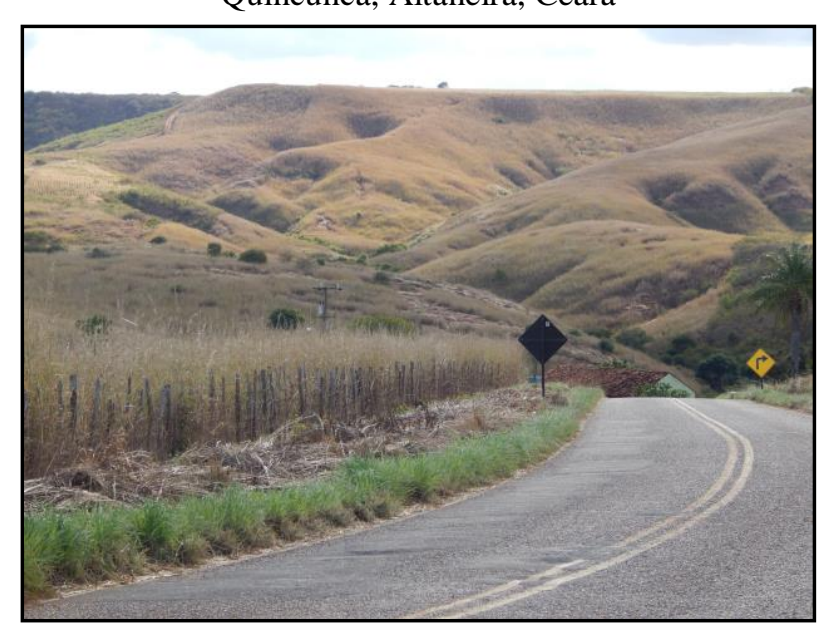

Foto: Frederico de Holanda Bastos, 2016

Figura 11: Exumação da etch surface nos setores circunvizinhos ao maciço do Quincuncá, Farias Brito, Ceará

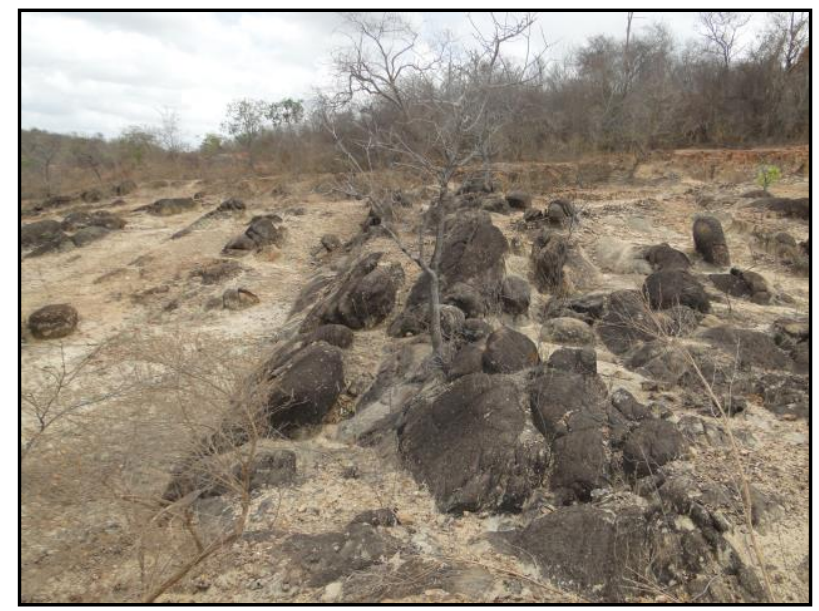

Foto: Frederico de Holanda Bastos, 2015

Além das áreas anteriormente apresentadas, no contexto geomorfológico do Estado do Ceará, também merece destaque a ocorrência de lateritas na superfície somital do glint da Ibiapaba (Figura 12). Tais ocorrências, ainda pouco estudadas, sustentam pequenos relevos de mesetas em cotas superiores a $700 \mathrm{~m}$. 
Figura 12: Crostas lateríticas no topo do glint da Ibiapaba, Tianguá, Ceará

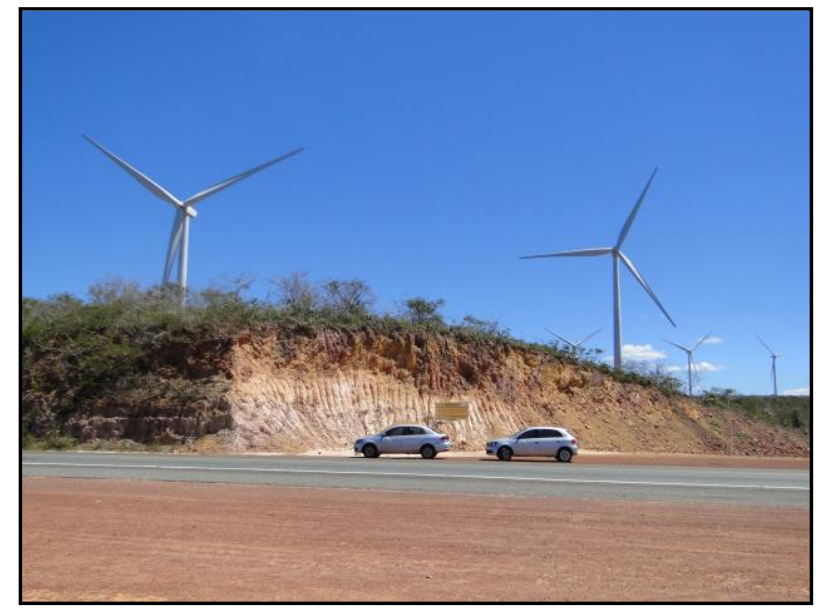

Foto: Frederico de Holanda Bastos, 2017

\section{Relevos cársticos}

De acordo com Elorza (2008), em regiões áridas com escassez da cobertura vegetal densa e solos pouco desenvolvidos (quantidade reduzida de $\mathrm{CO}_{2}$ ) constata-se uma limitação no desenvolvimento de feições de dissolução. Consequentemente as morfologias cársticas identificadas em ambientes secos podem ser interpretadas como feições herdadas de períodos onde a precipitação era mais expressiva, com condições paleoclimáticas mais úmidas (ELORZA, 2008; BIGARELLA et al., 2009).

A ocorrência de feições cársticas em áreas semiáridas do Nordeste brasileiro tendem a indicar condições paleoclimáticas úmidas associadas ao seu ápice de desenvolvimento. As mais expressivas ocorrências de cartes da Província Borborema situam-se na bacia Potiguar, sobretudo no Estado do Rio Grande do Norte, com fortes evidências de controle estrutural na sua gênese associado a deformações rúpteis nos calcários da Formação Jandaíra (CARNEIRO, et al. 2015). Na presente abordagem dar-se-á ênfase aos cartes associados com metacalcários Pré-Cambrianos da Província Borborema que apresentam formas exocárticas (Figura 13), de maneira mais abundante, e, em menor proporção, formas endocársticas (Figura 14).

No Estado do Ceará constata-se a ocorrência de cartes em metacalcários em diversos recortes espaciais, com destaque para os metacalcários da Unidade Independência com cartes nos esporões do maciço do Machado e de Baturité (Figura 15). Na serra do Machado encontra-se um carste muito interessante localizado no município de Tejuçuoca e denominado Furna dos Ossos, cujas condições climáticas atuais são bastante severas com totais pluviométricos atuais em torno 600mm (CAVALCANTE, 2016). Além das ocorrências 
anteriormente apresentadas, destaca-se o mais expressivo carste do Ceará que está associado ao Grupo Ubajara (Formação Frecheirinha), que ocorre nos escarpamentos do glint da Ibiapaba e na depressão sertaneja circunvizinha, onde se localizam também alguns inselbergs cársticos (Figura 16).

Figura 13: Formas exocársticas se destacando diante das caatingas nos esporões do maciço do Machado, Tejuçuoca, Ceará

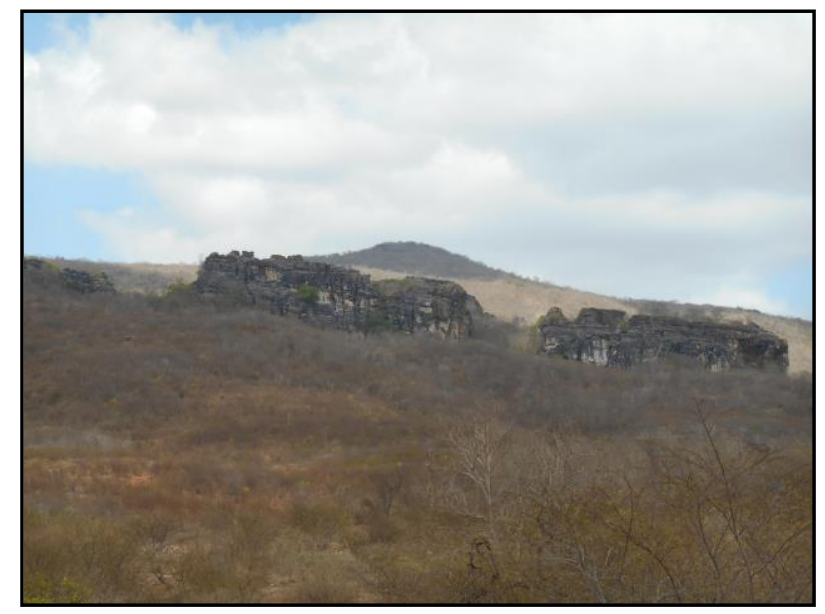

Foto: Daniel dos Reis Cavalcante, 2015

Figura 14: Espeleotemas da Furna dos Ossos nos esporões do maciço do Machado, Tejuçuoca, Ceará

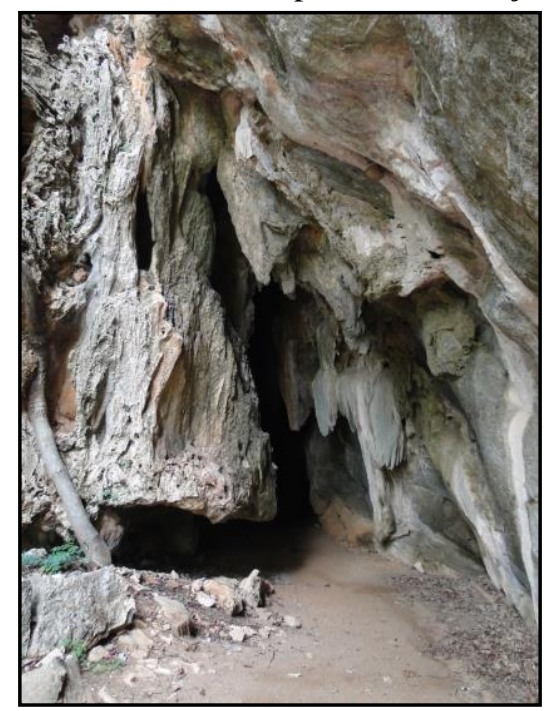

Foto: Frederico de Holanda Bastos, 2015 
Figura 15: Pináculos cársticos nos setores orientais circunvizinhos do maciço de Baturité, Barreira, Ceará

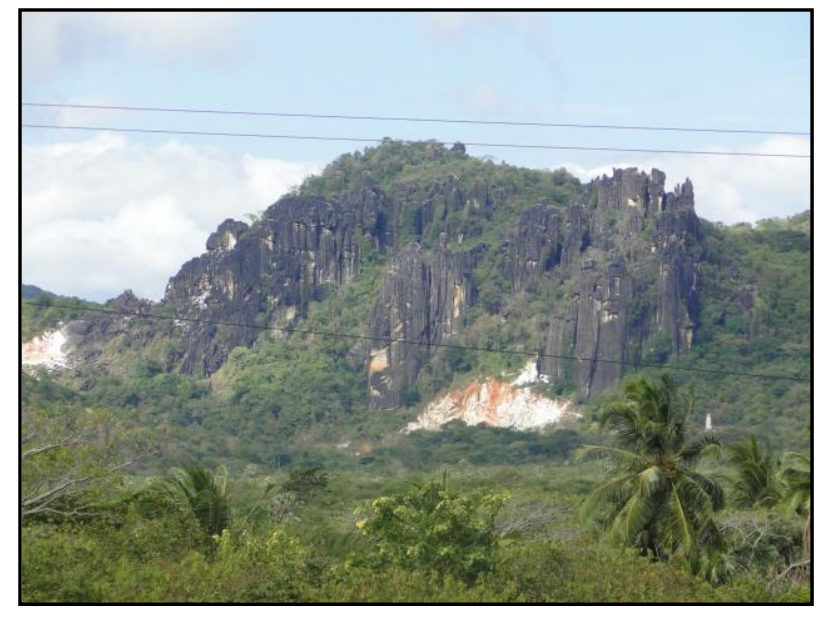

Foto: Frederico de Holanda Bastos, 2011

Figura 16: Inselbergs cársticos (um deles colapsado) no distrito de Araticum da depressão sertaneja situada no setor oriental do glint da Ibiapaba, Ubajara, Ceará

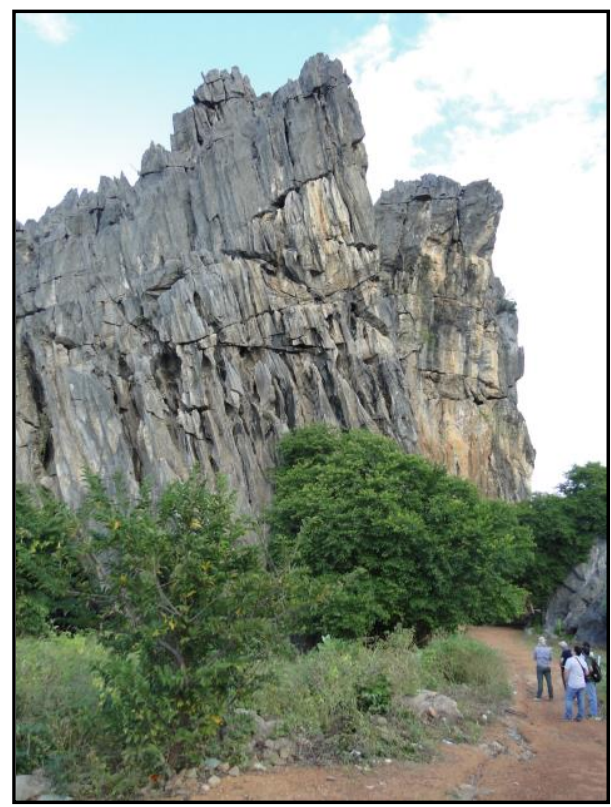

Foto: Frederico de Holanda Bastos, 2017

Apesar de o presente trabalho considerar a ocorrência de feições cársticas em áreas semiáridas como um indicador de paleoclima úmido, é importante destacar tais formas ainda estão em evolução nas condições climáticas atuais, contudo, acredita-se que seu ápice evolutivo, sobretudo quando se associa a formas endocárticas, se deve a climas mais úmidos do passado, quando as condições ambientais (clima, solo e vegetação) eram mais propícias ao desenvolvimento dessas feições. 


\section{CONSIDERAÇÕES FINAIS}

As evidências morfológicas de condições paleoclimáticas úmidas aqui apresentadas constituem elementos de grande relevância na interpretação de morfogênese regional, cujos modelos evolutivos de "Etchplanação" e de "Aplainamentos por Mudanças Climáticas" podem perfeitamente ser aplicados no contexto do semiárido brasileiro.

Contudo, é fundamental que, aliado a essas interpretações, disponha-se de métodos de geocronologia que permitam detalhar o contexto temporal dos eventos de maneira que se possa interpretar adequadamente a forma como cada contexto morfoestrutural aqui apresentado evoluiu.

Um dos grandes problemas do semiárido brasileiro é que os elementos naturais passíveis de serem datados encontram-se, em muitos casos, já erodidos pelas condições morfodinâmicas agressivas não restando muitos testemunhos para serem datados.

\section{REFERÊNCIAS}

AB'SABER, A. N. Depressões periféricas e depressões semi-áridas do Nordeste do Brasil. Bol. Paul. Geogr, 22, pp. 3-18, 1956.

AB SÁBER, A. N. Participação das superfícies aplainadas nas paisagens do Nordeste Brasileiro. IGEOG-USP, Bol. Geomorfologia, SP, n 19, 38p, 1969.

AB SÁBER, A. N. O Domínio Morfoclimático Semi-Árido das Caatingas Brasileiras. Geomorfologia, N 43. IG - USP. São Paulo, 1974.

ANDRADE, G. O.; CALDAS LINS, R. Introdução à morphoclimatologia do Nordeste do Brasil. 2a ed., revista. Inst. Ciên. Terra, Univ. Recife, vol. 3-4, pp. 17-28, 1965.

ANDRADE, G. O. Gênese do relevo nordestino: estado atual dos conhecimentos. Estad. Univ., Recife, 2-3 pp. 1-13, 1968.

ARTHAUD, M.H. Evolução Neoproterozóica do Grupo Ceará (Domínio Ceará Central, NE Brasil): da sedimentação à colisão continental brasiliana. 2007. 170 f. Brasília, 2007. Tese (Doutorado em Geociências) - Instituto de Geociências da Universidade de Brasília. Brasília, 2007.

BEHLING, H.; ARZ, H. W.; PÄTZOLD, J.; WEFER, G. Late Quaternary vegetational and climate dynamics in northeastern Brazil, inferences from marine core GeoB 31041.Quaternary Science Reviews, v. 19, n. 10, p. 981-994, 2000.

BÉTARD, F.; PEULVAST, J-P. Evolução morfoestrutural e morfopedológica do maciço de Baturité e de seu Piemont: do Cretáceo ao presente. p. 35-59. In: BATOS, F. H. (Org.). 
Serra de Baturité: uma visão integrada das questões ambientais. Fortaleza: Expressão Gráfica e Editor, 2010.

BIGARElla, J. J; BECKER, R. D.; SANTOS, G. F. Estrutura e Origem das Paisagens Tropicais e Subtropicais. Ed. UFSC, v. 1. Florianópolis, 2009.

BIGARELLA, J. J.; ANDRADE, G.O. Considerações sobre a estratigrafia dos sedimentos cenozóicos em Pernambuco (Grupo Barreiras). Univ. Rec., Inst. Ciên. Terra, Arquivos, 2, pp. 2-14, 1964.

BRASIL. Nova Delimitação do Semiárido Brasileiro. Ministério da Integração Nacional. Secretaria de Políticas e Desenvolvimento Regional. Brasília, 2005.

CAMPBELL, E. M.; TWIDALE, C. R. The various origins of minor granite landformas. Caderno Lab. Xeolóxico de Laxe, Coriña, vol. 20, pp. 281-306, 1995.

CARneIRO, M. A., BEZERRA, F. H. R., SilvA, C. C. N., MAIA, R. P. Controle estrutural do sistema cárstico epigenético na Formação jandaíra - Bacia Potiguar. Geociências (Online), v. 34, p. 199. São Paulo, 2015.

CAVAlCANTE, D. R. Considerações Geomorfológicas sobre o Carste do Município de Tejuçuoca, Ceará, Brasil. Trabalho de Conclusão de Curso de Graduação em Geografia da Universidade Estadual do Ceará (UECE). Licenciatura em Geografia. Fortaleza, 2016.

CORDEIRO, A. M. N. Morfoestrutura e Morfopedologia da Serra do Quincuncá e entorno, Ceará, Brasil. Tese de Doutorado. Programa de Pós-Graduação em Geografia da UECE (ProPGeo). 253pp. Fortaleza, 2017.

CORDEIRO, A. M. N., BASTOS, F. H. MAIA, R. P. Formações concrecionárias e aspectos genéticos e evolutivos do Maciço do Quincuncá, Província Borborema, Nordeste do Brasil. Revista Brasileira de Geomorfologia. v. 19, n. 2 (abr - jun), pp. 359-372, São Paulo, 2018.

CORREA, A. C. B; TAVRES, B. A. C; MONTEIRO, K. A; CAVALCANTI, L. C. S.; LIRA, D. R. Megageomorfologia e Morfoestrutura do Planalto da Borborema. Revista do Instituto Geológico, São Paulo, 2010.

DEMANGEOT, J. Essai sur le relief du Nord-Est brésilien. Ann. Géogr, 69 (372), pp. 157 176, 1960.

DRESCH, J. Les problèmes morphologiques du Nord-Est brésilien. Z. Geomorphol, 1, pp. 289-301, 1957.

ELORZA, M. G. Geomorfología. Pearson Educación, p. 920. Madrid, 2008. 
GURGEL, S. P. P.; BEZERRA, F. H. R.; CORRÊA, A. C. B.; MARQUES, F. O.; MAIA, R.

P. Cenozoic uplift and erosion of structural landforms in NE Brazil. Geomorphology, v. 186, pp. 68-84, 2013.

JESSEN, O. Reisen und forschungen in Angola. The Geographical Journal, v. 8, n. 4, p. 362-364, Berlin: D. Reimer, 397p, 1936.

KING, L. C. A geomorfologia do Brasil oriental. Rev. Bras. Geogr, 18 (2), pp. 147-265, 1957.

LIMA, D. L. S. Geomorfologia em Estruturas Graníticas: O caso do Maciço de Uruburetama, Ceará, Brasil. Dissertação de Mestrado. Programa de Pós-Graduação em Geografia da UECE (ProPGeo). 259pp. Fortaleza, 2018.

LIMA, M. da G. A história do intemperismo na Província Borborema oriental, Nordeste do Brasil: implicações paleoclimáticas e tectônicas. Tese (Doutorado em Geodinâmica). Programa de Pós-Graduação em Geodinâmica e Geofísica, Universidade Federal do Rio Grande do Norte, Natal, 594p, 2008.

MABESOONE, J. M.; CASTRO, C. Desenvolvimento geomorfológico do nordeste brasileiro. Bol. Núcleo Nordeste da SGB, Recife, 3, pp. 5-35, 1975.

MAIA, R. P.; BEZERRA, F. H. R. Condicionamento estrutural do relevo no Nordeste setentrional brasileiro. Mercator, v. 13, n. 1, pp. 127-141, 2014.

MAIA, R. P.; BASTOS, F. H.; NASCIMENTO, M. A. L.; LIMA, D. L. S.; CORDEIRO, A. M. N. Paisagens Graníticas do Nordeste Brasileiro. Edições UFC. 104 pp. Fortaleza, 2018. MIGÓN, P. Geomorphological landscapes of the world: granite landscapes of the world. Oxford University Press Inc., New York, 2006.

Bornhardt. In: GOUDIE, Andrew S. Encyclopedia of geomorphology. Londres: Taylor \& Francis e-Library, p. 92-93, 2006b.

Etching, etchplain and etchplanation. In: GOUDIE, Andrew S. Encyclopedia of geomorphology. Londres: Taylor \& Francis e-Library, p. 345-347, 2006c.

Granite geomorphology. In: GOUDIE, Andrew S. Encyclopedia of geomorphology. Londres: Taylor \& Francis e-Library, p. 490-493, 2006d.

Grus. In: GOUDIE, Andrew S. Encyclopedia of geomorphology. Londres: Taylor \& Francis e-Library, p. 501-503, 2006e.

Inselberg. In: GOUDIE, Andrew S. Encyclopedia of geomorphology. Londres: Taylor \& Francis e-Library, p. 564-566, 2006f. 
MILLOT, G. Géochemie de la surface et formes du relief. Societé Géologie Bulletin, Paris, v. 30, n. 4, p. D229-D233, 1977.

MILLOT, G. Planation of Continents by Intertropical weathering and pedogenetic processes. In: Proceedings of the II International Seminar on Laterization Processes, São Paulo, IGCP-129/IAGC, p.53-63, 1983.

NAHON, D. B. Introduction to the petrology of soils and chemical weathering. New York: John Wiley and Sons Ltd, 336p, 1991.

OLLIER, Clifford D. A two-cycle theory of tropical pedology. Journal of Soil Science, v. 10, n. 2, p. 137-48, 1959.

PEUlVAST, J-P.; ClAUDINO SALES, V. Mapa morfoestrutural do Ceará e áreas adjacentes do Rio Grande do Norte e da Paraíba. In: Brasil. Atlas digital de geologia e recursos minerais do Ceará. Mapa na escala 1:500.000. Fortaleza: Serviço Geológico do Brasil, 2003.

PEUlVAST, J-P.; CLAUDINO SALES, V. Stepped surfaces and Paleolandforms in the Northern Brasilian "Nordeste": Constraints on models of morfotectonic evolution. Geomorphology. v. 62, pp. 89-122, 2004.

PEULVAST, J-P., BÉTARD, F. A history of basin inversion, scarp retreat and shallow denudation: the Araripe Basin as a keystone for understanding long-term landscape evolution in NE Brazil. Geomorphology, 233, pp. 20 - 40, 2015.

SAADI, A. Neotectônica da Plataforma Brasileira: Esboço de Intepretação preliminar. Geonomos, MG. 1(1), pp. 1-15, 1993.

SAADI, A.; TORQUATO, J.R. Contribuição à neotectônica do Estado do Ceará. Revista de Geologia, Fortaleza - CE. 5, pp. 5-38, 1994.

SALGADO, A. A. R. Superfície de aplainamento: antigos paradigmas revistos pela ótica dos novos conhecimentos geomorfológicos. Revista Geografias. Belo Horizonte, vol, 3, n. 1, p. 64-78, 2007.

TARDY, Y. Pétrologie des latérites et des sols tropicaux. Paris: Elsevier Masson, 459p, 1993.

TRICART, J. Divisão morfoclimática do Brasil Atlântica Central. Boletim Paulista de Geografia, São Paulo, n. 31, pp. 3-4, 1959.

TWIDALE, C. R. The two-stage concept of landform and landscape development involving etching: origin, development and implications of an idea. Earth-Science Reviews, 57, p. 37-74, 2002. 
TWIDALE, C. R.; VIDAL ROMANÍ, J. R. Landforms and Geology of Granite Terrains. CRC Press Inc., Boca Raton, USA, 2005.

VASCONCELOS, P. M.; BRIMHALL, G. H.; BECKER, T. A.; RENNE, P. R. 40Ar/39Ar analysis of supergene jarosite and alunite: implications to the paleoweathering history of the western USA and West Africa. Geochimica et Cosmochimica Acta, v. 58, n. 1, p. 401420, 1994.

VITTE, A. C. Considerações sobre a teoria da etchplanação e sua aplicação nos estudos das formas de nas regiões tropicais quentes e úmidas. São Paulo, Revista Terra Livre, ano 1, n. 16, p. 11-24, 2001.

WANG, X.; AULER, A. S.; EDWARDS, R. L.; CHENG, H.; CRISTALLI, P. S.; SMART, P. L.; RICHARDS, D. A.; SHEN, C. C. Wet periods in northeastern Brazil over the past 210 kyr linked to distant climate anomalies. Nature, v. 432, p. 740-743, 2004. 